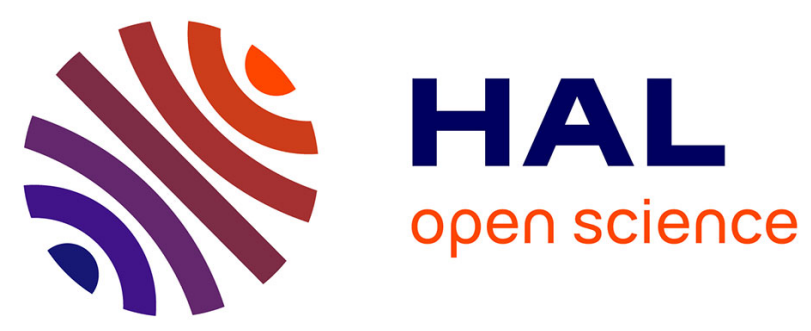

\title{
Indirect measurement and control of moisture content during dehydration performed by frying
}

\author{
G Trystram, Ioan-Cristian Trelea, A L Raoult-Wack, A Diaz, Francis F.
} Courtois

\section{- To cite this version:}

G Trystram, Ioan-Cristian Trelea, A L Raoult-Wack, A Diaz, Francis F. Courtois. Indirect measurement and control of moisture content during dehydration performed by frying. Drying Technology, 1999, 17 (7\&8), pp.1627-1637. 10.1080/07373939908917641 . hal-01537202

HAL Id: hal-01537202

https://hal-agroparistech.archives-ouvertes.fr/hal-01537202

Submitted on 12 Jun 2017

HAL is a multi-disciplinary open access archive for the deposit and dissemination of scientific research documents, whether they are published or not. The documents may come from teaching and research institutions in France or abroad, or from public or private research centers.
L'archive ouverte pluridisciplinaire HAL, est destinée au dépôt et à la diffusion de documents scientifiques de niveau recherche, publiés ou non, émanant des établissements d'enseignement et de recherche français ou étrangers, des laboratoires publics ou privés. 


\title{
INDIRECT MEASUREMENT AND CONTROL OF MOISTURE CONTENT DURING DEHYDRATION PERFORMED BY FRYING
}

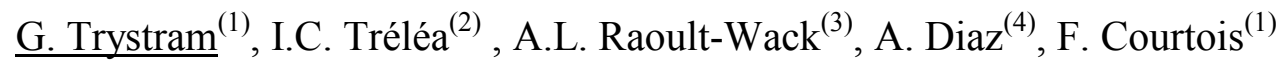 \\ 1 ENSIA-INRA Food Process Engineering Department, France \\ 2 INAPG-INRA-LGMPA Department, France \\ 3 CIRAD AMIS, France \\ 4 University DelValle, Colombia
}

Keywords: Drying, Frying, Measurement, Control

\begin{abstract}
Frying is one of the way for performing drying of food material that permits to obtain very short duration. However the control of such operation is difficult because of the immersion of product into hot oil bath that imply difficult or impossible sensors implementation. Such problems are encoutered for Dehydration Soaking Process (DISP). In the case of Batch drying using frying of food stuffs, an original approach is presented. An indirect measurement of moisture content is performed as a combination of easy to do oil bath temperature mesasurement and an estimator. Validation is provided and performance is well established. Because of the ability of moisture content real time measurements, a control strategy is studied and put into practice. An optimal predictive controller is proprosed, able to put into practice several kind of control objectives. Results are discussed and extension of the strategy is introduced.
\end{abstract}




\section{INTRODUCTION}

Drying of solid products (pieces or slices) is possibe using several approaches. One of these is the frying based approach which is an interesting one because of the short duration ( $90 \mathrm{~s}$, depending the thickness of the product). Like with dehydration Impregnation soaking process, frying imply an immersion into a liquid (hot oil). Due to that fact, it becomes very difficult to perform real time measurements. Mainly because the most important variables evolution are not easy to follow with sensors. Important variables are moisture and fat content of product pieces, but other quality variables (colour for example) are important too. As a consequence the control of such operations is hard. If fryer is used as a drying operation, the fat impregnation must be controlled. It is the same for nutrionnal point of view. During batch operation, the control, and eventually the minimization of the duration of the operation is necessary. It is than important to design and validate control algorithm for such processes.

The purpose of the paper is to present an application of control science that permits first to estimate unmeasurable variables (moisture content here) from easy to do measurements (oil bath temperature), using specific appropriated algorithm. The second objective is to establish the ability af optimal control to respect constraints and to reach an optimal behaviour. Application is the drying under frying of plantain banana slices.

\section{State estimation techniques}

In control theory, state estimation means reconstruction of the unmeasured part of the process state, in our case the moisture content $W$ and the oil content $O$, from the available measurements (oil temperature $T$ and heating power $Q$ ), using a process model, which in our case consists in a heat balance and a dynamic model of the drying kinetics. 
The classical Luenberger state estimator (Luenberger, 1971) uses a linear dynamic process model with a correction term, based on the difference between the predicted and the measured process output. A nontrivial task is the selection of the correction gain matrix, in order to achieve the desired behavior: convergence speed, robustness with respect to measurement noise and modeling error, etc. A widely used version of this observer is the celebrated Kalman filter (Kalman et al., 1961), where the gain matrix is calculated to achieve the minimum variance of the estimated state, under certain statistical hypothesis on the disturbances. In practice, all required statistical information is rarely available, and the noise covariance matrices are regarded as tuning parameters (Maciejowski, 1989).

All these techniques use linear process models, but batch processes do not have an operating point and the local linear approximation is rarely satisfactory. Nonlinear techniques, like the extended Kalman filter, have been developed (Lee et al, 1994; Yu et al., 1994) but they are difficult to tune, because the estimator behavior depends on the current state, and the tuning parameters do not have an obvious meaning in terms of process variables.

Recently, moving horizon state estimators based on fitting of nonlinear dynamic models to online measurements have been developed (Moraal et al., 1995; Zimmer, 1993). They have good robustness properties and are easy to tune, but require more complex on-line computations compared to traditional techniques. Boillereaux et al. (1995) show that such estimators can also compute upper bounds on the estimation error, which may be very useful in process control.

\section{MATERIALS AND METHODS}

\section{Frying experiments}

Experiments are perfomed using a batch fryer laboratory apparatus. The volume of oil is 5 liter. Agitation is provided and a temperature controller is implemented wich permits the control of oil bath temperature through a set of electrical heat resistor. Refined palm oil is used. 
The product used during experiment are plantain banana (Musa paradisiaca L.) slices (Diaz et al., 1996). Slices thickness is $2.3 \mathrm{~mm} .0 .5 \mathrm{kG}$ of products is used in each experiment.

Moisture content is measured with a 24 hours experiment in controlled oven at $105{ }^{\circ} \mathrm{C}$. Oil content is measured with a classical hexan soxhlet extraction method. All the calculation are performed using the Matlab library.

\section{Estimation algorithm}

The principle of the moving horizon state estimation (Boillereaux et al. 1995) is explained in figure 1 . The model simulates the oil temperature over the time interval $\tau_{H}=300 \mathrm{~s}$ (the estimation horizon), where measured values are also available. The simulated oil temperature depends on the moisture content, through the heat balance equation (the state $W$ is observable through the available measured output $T_{m e s}$ ). An optimization algorithm selects the moisture content at the beginning of the estimation horizon that best fits the measured temperature evolution, in a quadratic sense.

Let $y_{\text {mes }}=\left[\begin{array}{lllll}T_{\text {mes } i_{1}} & T_{\text {mes }} i_{2} & \ldots & T_{\text {mes }} n_{M}\end{array}\right]^{T}$ be the set of $n_{M}$ measurements available between $t_{P}$ and $t_{P}-\tau_{H}$. Let $\mu_{e}$ be the function expressing the dependence of the oil temperature $T$, at the moments when measurements are available, on the moisture content $W$, at the beginning of the estimation horizon. It is in fact the process model, where the independent variable is the moisture content, and the predicted variable the oil temperature at some fixed moments. The estimated moisture content is the value which minimizes the following quadratic criterion :

$$
W_{\text {est } i_{1}}=\arg \min \left(\mu_{e}\left(W_{i_{1}}\right)-y_{\text {mes }}\right)^{T}\left(\mu_{e}\left(W_{i_{1}}\right)-y_{\text {mes }}\right) \quad n_{M} \geq 4
$$

After the determination of $W$ at the moment $t_{P}-\tau_{H}$, the simulation of the model up to $t_{P}$ gives an estimation of the full state $x=\left[\begin{array}{lll}T & W & O\end{array}\right]^{T}$ at the present moment. The oil temperature $T$ is filtered, as opposed to taking the last available measurement, which is more affected by noise. The oil content $O$ is simply simulated, because it is unobservable from the given process output. 
This means that modeling errors concerning oil content evolution and errors in initial oil content can not be corrected on line.

\section{Frying model}

\section{Hypotheses}

A black box model is used for the water loss and oil gain kinetics, and a simplified heat balance for the oil temperature. The following hypotheses are used : (a) The heat comes exclusively from the heating resistance; (b) The heat is used only for water evaporation; (c) The total heat capacity of the product is negligible compared to that of the frying oil; (d) The water loss and oil gain kinetics are first order and independent; (e) At constant temperature and agitation, the water loss and oil gain are linear, but their parameters linearly depend on the operating conditions. The overall model is thus bilinear. Most of this hypotheses are consistent with previous results (Diaz et al., 1996).

\section{Process variables}

The process state $x$ consists of the oil temperature $T$, the moisture content $W$, expressed in dry basis without oil, and the oil content $O$ expressed in dry basis without oil. The model is valid for temperatures comprised between 130 and $170^{\circ} \mathrm{C}$. The control inputs $u$ consist of the heating power $Q$, comprised between 0 and $1000 \mathrm{~W}$, and the agitation $A$, comprised between 0 and $100 \%$. The only measured output $y$, which gives information on the process state, is the oil temperature $T_{\text {mes. }}$

$$
x=\left[\begin{array}{lll}
T & W & O
\end{array}\right]^{T}, \quad u=\left[\begin{array}{ll}
Q & A
\end{array}\right]^{T}, \quad y=T_{\text {mes }}
$$

Possible disturbances include product properties (model coefficients), the amount of frying oil and of product, heat loss other than by water evaporation, interdependence between moisture and oil kinetics, initial product state, initial oil temperature, etc

\section{Model equations}


Let $\tau_{e}=15 \mathrm{~s}$ be the sampling time, $i$ the number of the sampling instant and $h$ the model parameter matrix. The discrete-time dynamic model is:

$$
\begin{aligned}
& T_{i}=T_{i-1}+\frac{M_{s} C_{W v a p}}{M_{O} C_{O}}\left(W_{i}-W_{i-1}\right)+\frac{\tau_{e}}{M_{O} C_{O}} Q \\
& W_{i}=\left(h_{11} T_{i-1}+h_{12} A_{i-1}+h_{13}\right) W_{i-1}+h_{14} T_{i-1}+h_{15} \\
& O_{i}=\left(h_{21} T_{i-1}+h_{22} A_{i-1}+h_{23}\right) O_{i-1}+h_{24} T_{i-1}+h_{25}
\end{aligned}
$$

Numerical values used are : $T_{0}=130$ to $170^{\circ} \mathrm{C}$ depending on the experiment, $W_{0}=1.8 \mathrm{~kg}$ water by $\mathrm{kg}$ of dry product without oil, $O_{0}=0.05 \mathrm{~kg}$ water by $\mathrm{kg}$ of dry product without oil, $M_{S W O 0}=0.1 \mathrm{~kg}$, initial product mass (including moisture and oil), $M_{S}=M_{S W O 0} /\left(1+W_{0}+O_{0}\right)$

mass of dry product without oil, $C_{W v a p}=2443000 \mathrm{~J} / \mathrm{kg}$ water, $M_{O}=5 \mathrm{~kg}$ frying oil and $C_{O}=1800 \mathrm{~J} /(\mathrm{kg} \mathrm{K})$, specific oil heat capacity. The model coefficient matrix, computed using 18 frying kinetics, is :

$$
h=\left[\begin{array}{ccccc}
-5.8894 \cdot 10^{-3} & -1.2320 \cdot 10^{-4} & 1.6016 & 8.0489 \cdot 10^{-5} & 3.1378 \cdot 10^{-3} \\
-1.7585 \cdot 10^{-3} & 2.2005 \cdot 10^{-4} & 1.1718 & 4.6999 \cdot 10^{-4} & -3.5778 \cdot 10^{-2}
\end{array}\right]
$$

\section{Optimal controller}

The control variables are the heating power $P$ and the agitation $A$. Their evolution is piecewise linear. At every sampling time, the control algorithm optimizes the power and the agitation at 5 future moments, as well as the stop time, that is 11 parameters (Trelea et al., 1998). Before the frying begins, the initial oil temperature is optimized as well (12 parameters).

\section{Optimal control in ideal conditions}

Two scenarios A and B are discussed in the following, corresponding to two different goals :

A Minimize the final oil content, subject to $\min O_{\text {Stop }}$

a final moisture content lower than a $W_{\text {Stop }} \leq 0.05 \mathrm{~kg} / \mathrm{kg}$ 
specified limit.

B Minimize the processing time, subject to $\min t_{\text {Stop }}$ specified final moisture and oil contents. $\quad W_{\text {Stop }}=0.07 \mathrm{~kg} / \mathrm{kg}$

$$
O_{\text {Stop }}=0.50 \mathrm{~kg} / \mathrm{kg}
$$

In all cases, the control variables and the processing time must stay between specified limits :

$$
0 \leq Q \leq 1000 \mathrm{~W}, \quad 0 \leq A \leq 100 \%, 130 \leq T \leq 170^{\circ} \mathrm{C}, 15 \leq t_{\text {Stop }} \leq 600 \mathrm{~s}
$$

The optimal control strategy, in the case of a perfect model and without disturbances, is shown in figure 2 .

In the case of goal A, the optimal strategy consists in maintaining zero agitation and oil temperature as close as possible to its upper limit, which insures fast water evaporation ( 3 minutes) and a low oil content. At the beginning, the heating power is maximum, in order to compensate for the evaporation heat. At the end, the power is reduced in order to satisfy the upper temperature bound.

In the case of goal $\mathrm{B}$, the optimal strategy consists in maintaining maximum agitation and a relatively low oil temperature for a long time ( 8 minutes), in order to get higher water and oil contents. It must be stressed that the final oil content is higher at lower temperatures, as confirmed by experimental data in figure 3. Initial oil temperature and the heating power are adjusted to get the best temperature profile, while satisfying the constraints.

\section{RESULTS AND DISCUSSION}

\section{Frying model validation}

Figure 3 shows the simulated frying kinetics, together with the corresponding experimental data (3 repetitions of each experiment), for different combinations of operating conditions (temperature and agitation). The kinetics are simulated using a constant temperature hypothesis (small amount of product in a large amount of frying oil). It appears that model accuracy corresponds to the repeatability of experiments. The moisture content model is significantly better than the oil content model, due to a smaller dispersion of experimental points. Both models 
appear satisfactory for the assigned goal, namely state estimation and control of the frying process.

\section{State estimation}

The state estimator is tested in the following conditions :

-The "true" state values are supplied by a perturbed model $h_{P}$, with coefficients selected randomly, with mean $h$ and standard deviation $\sigma_{h}$, estimated from the experimental data in figure 3 .

$$
h_{P}=\left[\begin{array}{ccccc}
-5.8289 \cdot 10^{-3} & -1.1482 \cdot 10^{-4} & 1.6070 & 8.1692 \cdot 10^{-5} & 6.0419 \cdot 10^{-3} \\
-1.7753 \cdot 10^{-3} & 2.2105 \cdot 10^{-4} & 1.1750 & 5.0142 \cdot 10^{-4} & -3.6870 \cdot 10^{-2}
\end{array}\right]
$$

-The true initial moisture content is $2.5 \mathrm{~kg} / \mathrm{kg}$, rather than $1.8 \mathrm{~kg} / \mathrm{kg}$ as assumed by the estimation algorithm.

-The true initial oil content is $0.15 \mathrm{~kg} / \mathrm{kg}$, rather than $0.05 \mathrm{~kg} / \mathrm{kg}$ as assumed by the estimation algorithm.

-The oil temperature measurement is affected by a random noise, with standard deviation of $1^{\circ} \mathrm{C}$.

Despite modeling errors, initial state error and measurement noise, the state estimation works satisfactorily, as shown in figure 4. The oil temperature measurement appears filtered. The moisture content estimations gradually converge to their true values, despite the large initial error. Oil content estimations do not converge to their true values. This is expected, because the oil content is unobservable from the oil temperature measurement alone. The impact on the control strategy depends on the control goal, as discussed below.

\section{Optimal control}

The impact of various disturbances on the optimal control strategy is shown in figure 5 . In the example $A_{1}$, the initial oil temperature is lower than expected $\left(160\right.$ instead of $\left.170^{\circ} \mathrm{C}\right)$. This is immediately detected through the temperature measurement and compensated by a longer heating time. The estimated state coincides with the true one. The constraints are satisfied but the oil content is slightly higher $(5.7 \%)$, because of the lower average temperature. 
In the example $\mathrm{A}_{2}$, the "true" process is represented by the parameters $h_{P}$. The temperature and the moisture content are well estimated, because the uncertainties are small (figure 3) and the states are observable. The oil content model is less accurate, and the temperature measurement does not help in detecting modeling errors. The constraints are satisfied and the control strategy used is still optimal (it minimizes indeed the oil content), but the estimated value of the optimum is wrong.

In the example $\mathrm{B}_{1}$, more product is processed than initially assumed $\left(M_{S W O 0}=0.12 \mathrm{~kg}\right.$ instead of $0.10 \mathrm{~kg}$ ). The moisture content is slightly overestimated. The faster temperature decrease due to extra product is interpreted as a higher moisture content. The oil is slightly heated at the beginning, in order to satisfy the $130^{\circ} \mathrm{C}$ constraint. The constraints are satisfied and the cost function optimum is unchanged.

In the example $\mathrm{B}_{2}$, the initial moisture content is higher than assumed $(2.5 \mathrm{~kg} / \mathrm{kg}$ instead of 1.8$)$ and the temperature sensor is disconnected during the first $200 \mathrm{~s}$. The sensor "failure" prevents detecting the disturbance from the very beginning. The temperature is overestimated, because there is more water to evaporate than expected, and the moisture content is underestimated. The estimated values are improved as soon as measurements become available. The final heating starts earlier. The constraints are satisfied and the cost function optimum is unchanged.

\section{CONCLUSIONS}

Two kind of results must be highlighted.

First the drying of food material is possible using fryers and the control of such operations becomes possible. Short drying duration are observed. A simple bilinear model is validated and optimal under constraint automatic control is performed. 
Second, an interesting approach is presented for the on line measurement of not easy to do measurement. Even if sensors are not available, it is possible to use simple sensors, like here temperature sensor, and to rebuild the information which the most interesting one. The application presented here, dealing with moisture content measurement using an estimation technique can be extended to many other drying processes, performed as batch or continuous operations.

Ackoledgement: We acknoledge Olivier VITRAC for his help during the experimentation in Colombia.

\section{REFERENCES}

Luenberger, D.G., 1971, An introduction to observers. IEEE Transactions on Automatic Control. 16, pp. 596-602.

Kalman, R. E., and Bucy, R. S., 1961, New results in linear filtering and prediction theory. Transactions ASME, 83(D), pp. 95-108.

Maciejowsky, J. M., 1989, Multivariable feedback design. Addison-Wesley.

Lee, J. H., and Ricker, N. L., 1994, Extended Kalman filter based nonlinear model predicted control. Industrial engineering and chemistry research, 33, 1530-1541.

Boillereaux, L. and Flaus, J. M. 1995. A new algorithm for real time adaptive state estimation. AARTC'95, 3rd IFAC/IFIP Workshop on Algorithms and Architectures for Real Time Control, Ostend, Belgium.

Moraal, P. E. and Grizzle, J. W. (1995). Observer design for nonlinear systems with discrete time measurements. IEEE Transactions on Automatic Control 40, pp. 395-404.

Yu, Z. H., Li, W., Lee, J. H. and Morari, M. 1994, State estimation based model predictive control applied to shell control problem: a case study. Chemical Engineering Science 49, pp. 285301.

Zimmer, G. 1993, A new algorithm for approximating the states of nonlinear systems. International Journal of Systems Science 24, pp. 778-788. 
Trelea, I. C., Alvarez, G. and Trystram, G., 1998. Nonlinear predictive optimal control of a batch refrigeration process. Journal of Food Process Engineering, 21, pp. 1-32.

Diaz, A., Totte, A., Giroux, F., Reynes, M. and Raoult-Wack, A. L. (1996). Deep-fat frying of plantain (Musa paradisiaca L.). I. Characteristaion of control parameters. Lebensm.-Wiss. U.Technol. 29: 489-497. 


\section{List of figures}

Figure 1. Moving horizon state estimation. Measured (o) and predicted ( - ) oil temperature, for various moisture contents. $t_{\mathrm{P}}$ : present time. $\tau_{\mathrm{H}}$ : estimation horizon.

Figure 2. Optimal control in ideal conditions. Evolution of the predicted variables (-), measured values ( $\bullet$ ), estimated values (o) and constraints (- - ).

Figure 3. Comparison of experimental kinetics (o) of moisture and oil content with model simulations (-), for different temperature - agitation combinations.

Figure 4. Validation of the moving horizon state estimation. Measured values $(\bullet)$, true values not seen by the estimation algorithm (o), estimated values (-), constraints (- - -).

Figure 5. Optimal control in presence of disturbances. Predicted $(-)$, measured $(\bullet)$, true $(\cdots)$ and estimated (o) values. Constraints (- - ). 


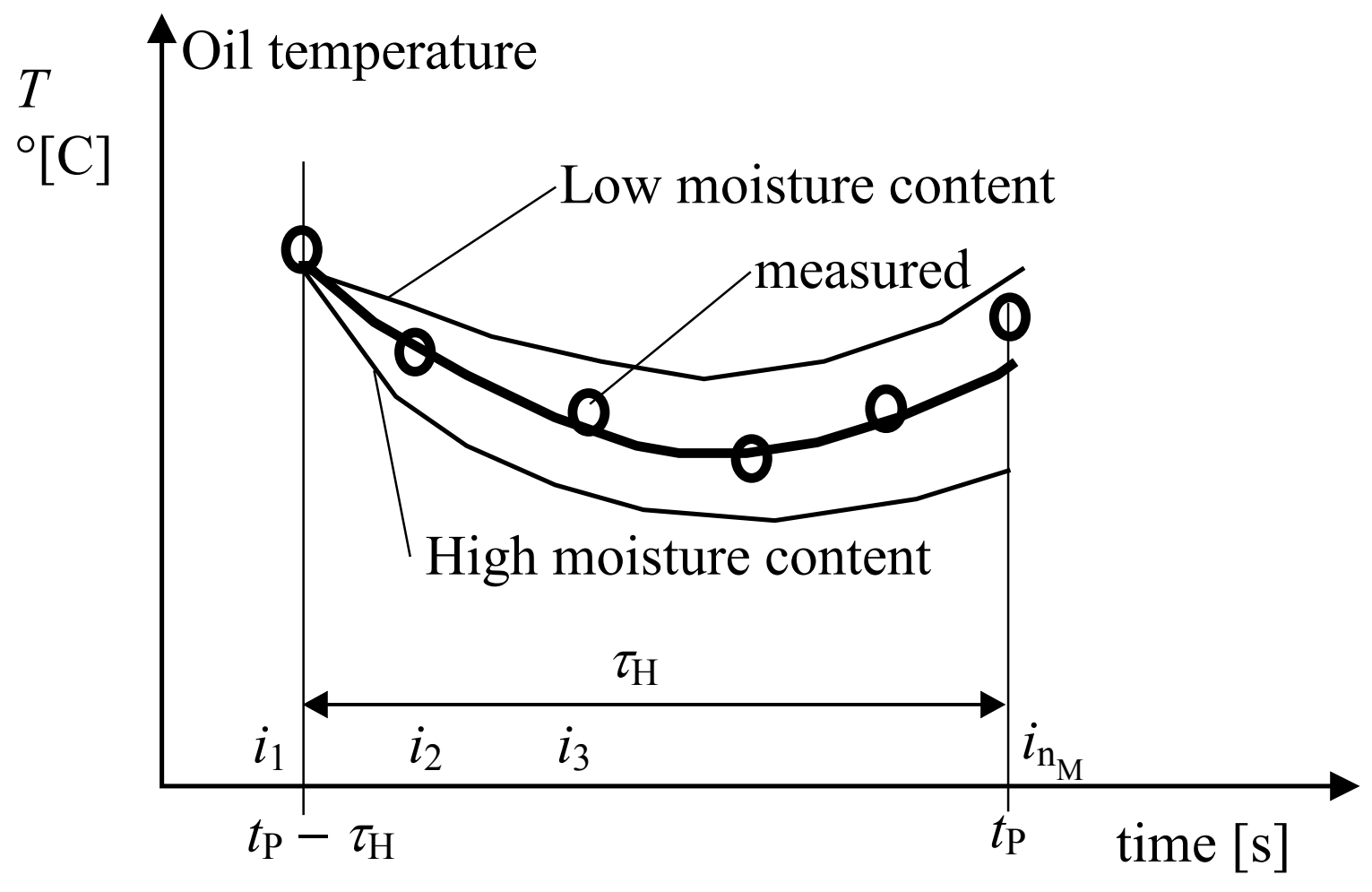


A
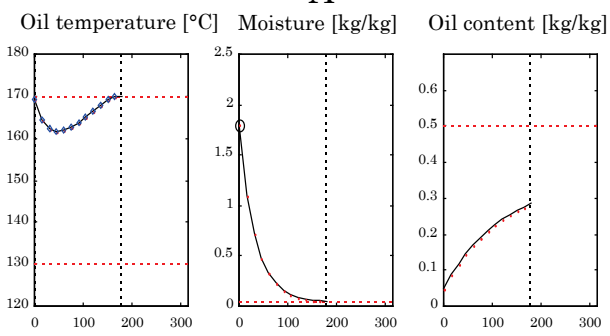

Heating power [W]

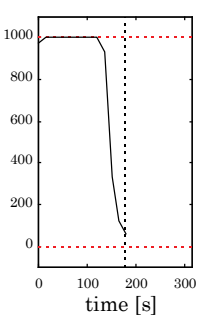

Agitation [\%]

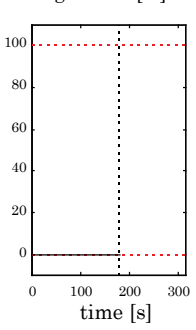

$W_{\text {Stop }}=0.05 \mathrm{~kg} / \mathrm{kg}$

$O_{\text {Stop }}=0.28448 \mathrm{~kg} / \mathrm{kg}$
B
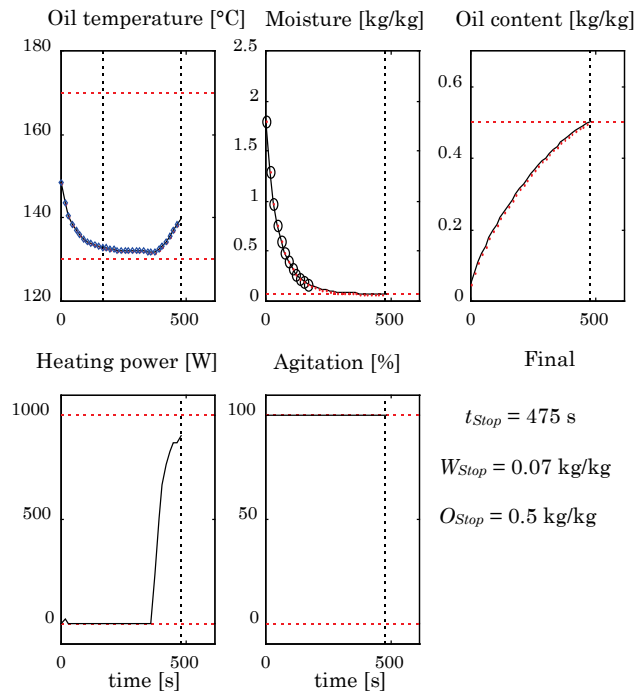

$t_{\text {Stop }}=475 \mathrm{~s}$

$W_{\text {Stop }}=0.07 \mathrm{~kg} / \mathrm{kg}$

$O_{\text {Stop }}=0.5 \mathrm{~kg} / \mathrm{kg}$ 
Moisture content [kg/kg]

Oil content [kg/kg]
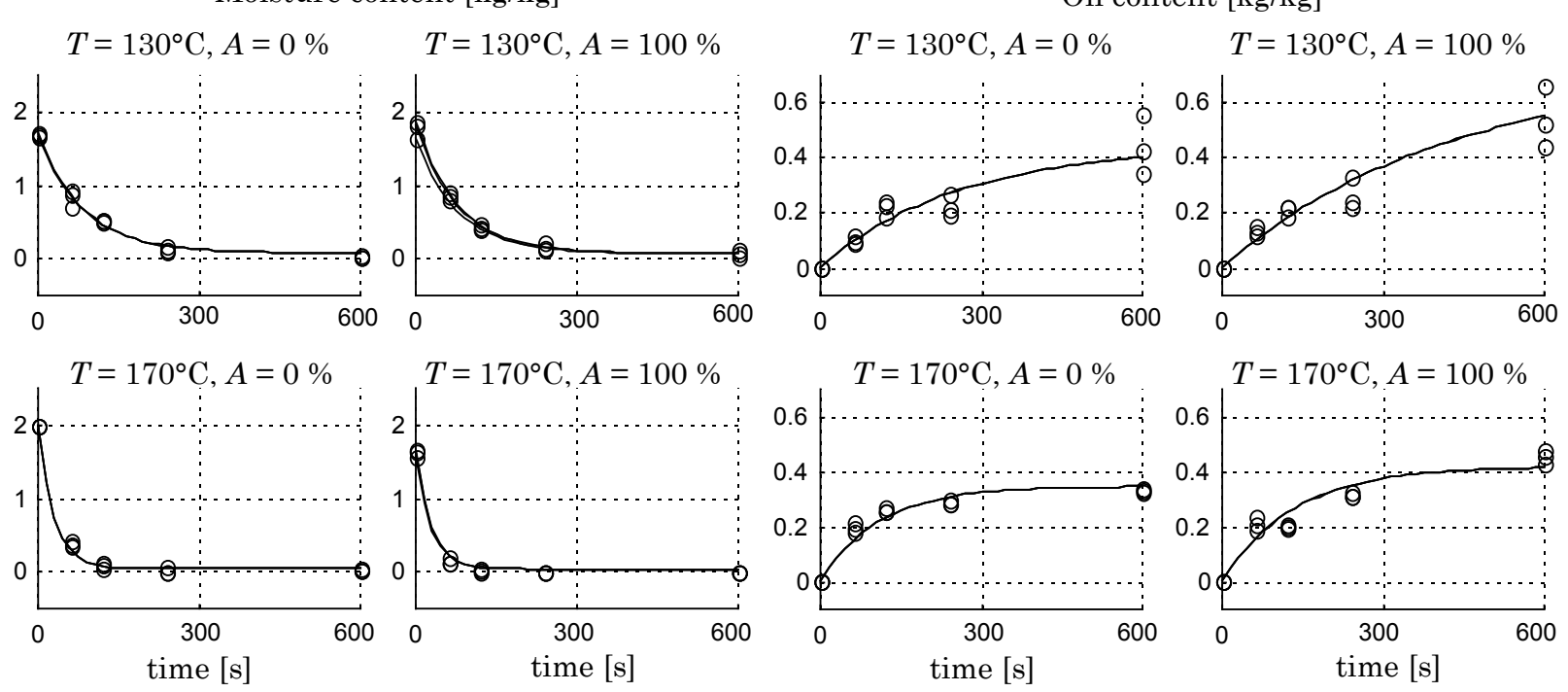

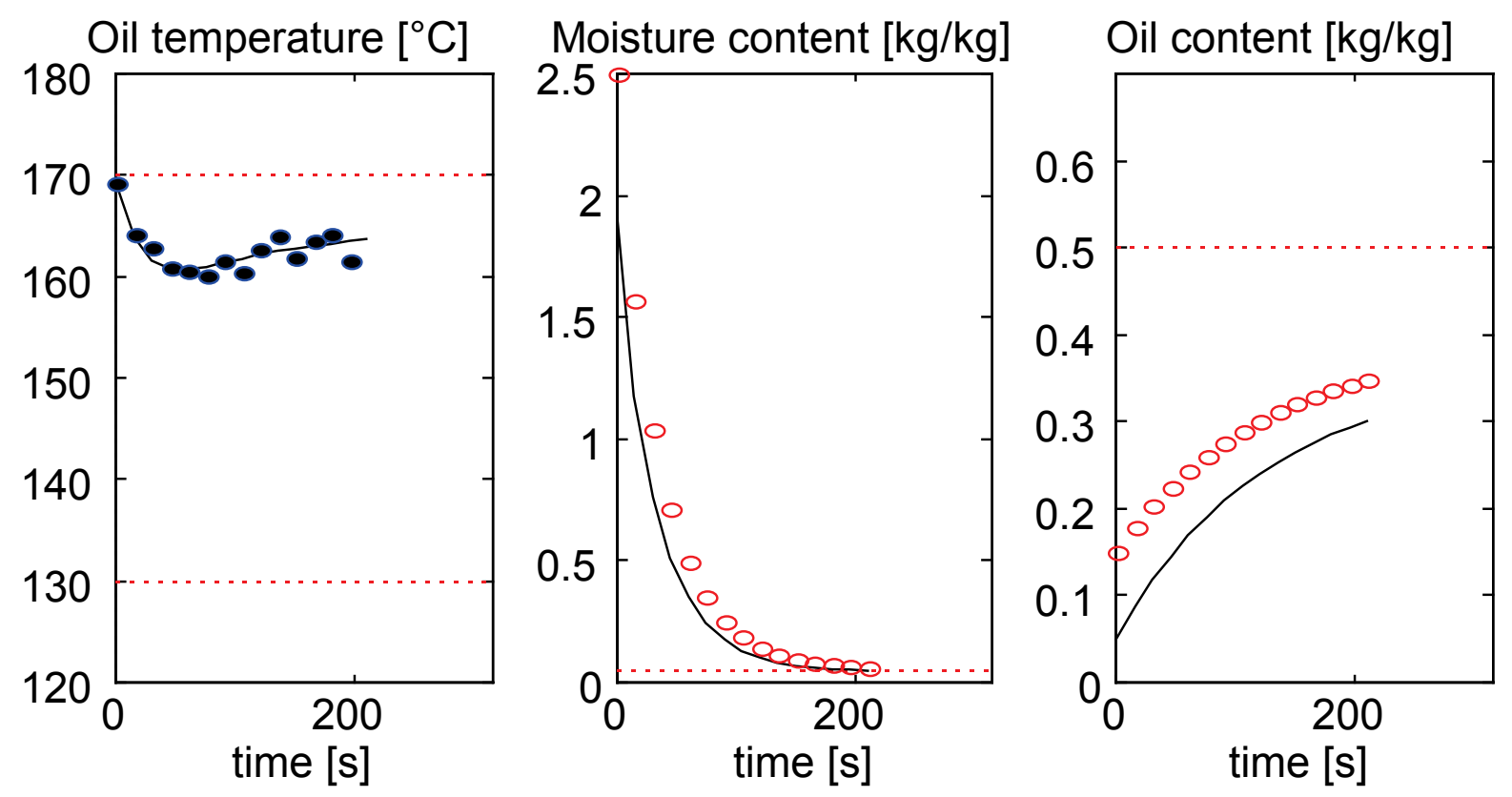
$\mathrm{A}_{1}$
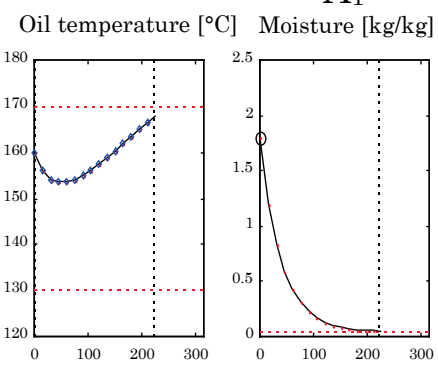

Agitation [\%]

Heating power [W]
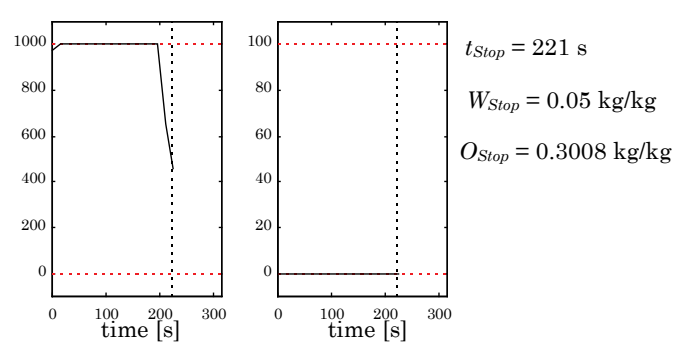

$\mathrm{A}_{2}$

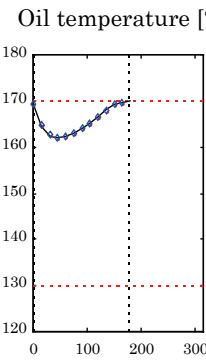

Heating power [W]
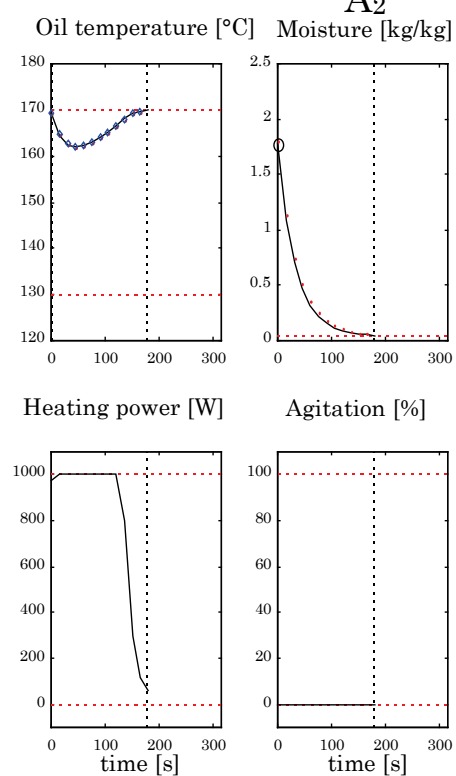

Agitation [\%]

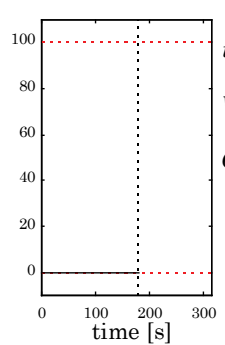

Oil content $[\mathrm{kg} / \mathrm{kg}]$

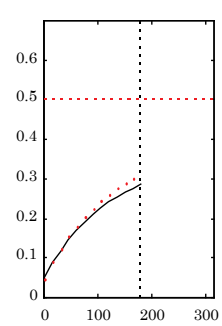

$\mathrm{B}_{1}$

Oil content $[\mathrm{kg} / \mathrm{kg}]$

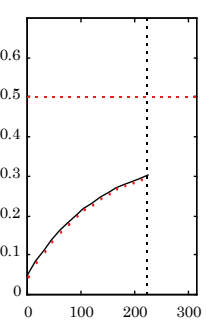

Final

$t_{\text {Stop }}=221 \mathrm{~s}$

$W_{\text {Stop }}=0.05 \mathrm{~kg} / \mathrm{kg}$

$O_{\text {Stop }}=0.3008 \mathrm{~kg} / \mathrm{kg}$

Final

$t_{\text {Stop }}=177 \mathrm{~s}$

$W_{\text {Stop }}=0.05 \mathrm{~kg} / \mathrm{kg}$

$O_{\text {Stop }}=0.283 \mathrm{~kg} / \mathrm{kg}$
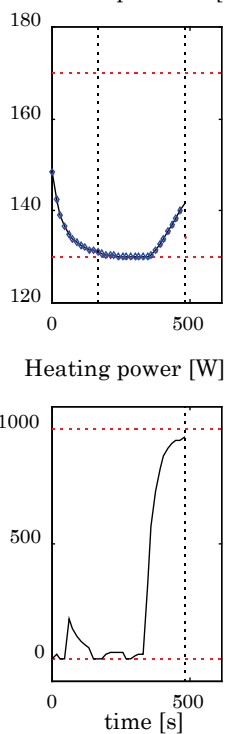

$\mathrm{B}_{2}$

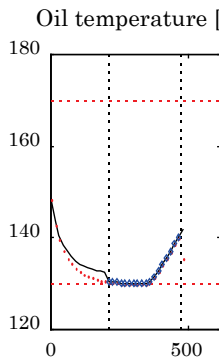

Heating power [W]
Oil temperature $\left[{ }^{\circ} \mathrm{C}\right]$ Moisture $[\mathrm{kg} / \mathrm{kg}]$

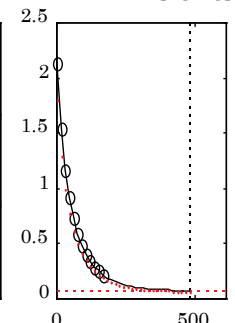

Oil content $[\mathrm{kg} / \mathrm{kg}]$
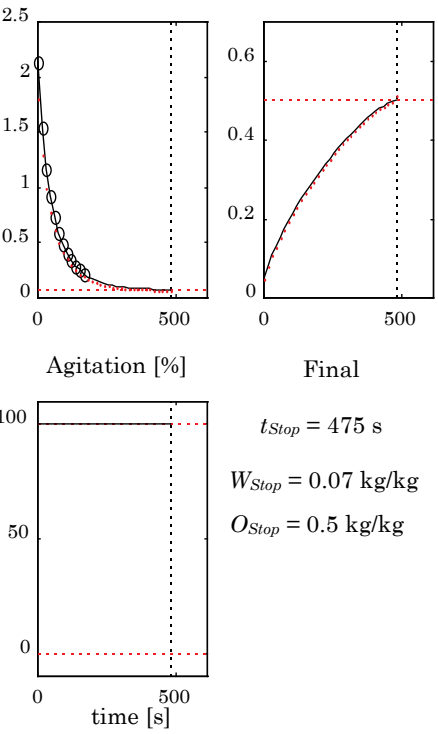

Final

$$
t_{\text {Stop }}=475 \mathrm{~s}
$$

$W_{\text {Stop }}=0.07 \mathrm{~kg} / \mathrm{kg}$

$O_{\text {Stop }}=0.5 \mathrm{~kg} / \mathrm{kg}$

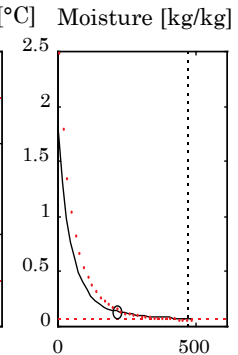

Oil content $[\mathrm{kg} / \mathrm{kg}]$

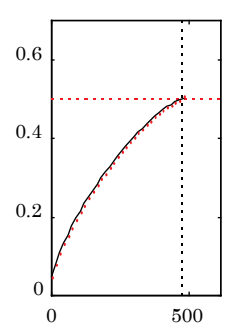

Agitation [\%]

Final
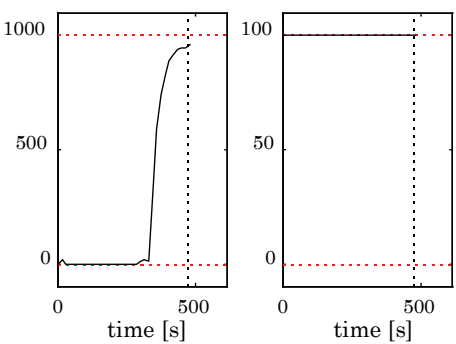

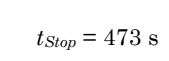

$W_{\text {Stop }}=0.07 \mathrm{~kg} / \mathrm{kg}$

$O_{\text {Stop }}=0.5 \mathrm{~kg} / \mathrm{kg}$ 